\title{
Researching Tenants and Residents Association and Local Authority Collaboration: the value of a grounded theory approach and ethnography
}

\author{
Rob Dalziel* \\ University of Birmingham
}

\begin{abstract}
In this paper I elaborate on my reasons for adopting a qualitative research strategy that comprised a novel grounded theory approach and ethnography to examine and analyse the management of tenants and residents association (TARA) and local authority collaboration. The main questions that are addressed concern decisions made about the sort of methodology and methods that could be used to obtain people's different perspectives on collaboration. I eventually adapted aspects of the grounded theory method to produce a grounded theory approach that fitted better with my ethnographic work and understanding TARA and local authority relationships in a large city in the north of England. A discussion of the usefulness of grounded theory includes views on the value of a grounded theory approach and ethnography to collect rich data on activities in complex and 'messy' real life situations. Finally, some key research findings and the implications of my research for other researchers in the future involved in studying phenomena and events in real life situations are set out.
\end{abstract}

Keywords: Tenants and residents association, local authority, grounded theory, ethnography, collaboration.

\section{Introduction}

I became interested in TARA and local authority relations during my time as a Labour councillor, in the 1990s, in a small steel town in the East Midlands. Then, in 2001, I adopted a qualitative research strategy to examine and analyse the management of TARA and local authority collaboration in a large industrial city in the north of England. TARAs vary in size, and the geographical area that they cover, which can range from a single tower block or few streets up to a large estate that consists of many hundreds of houses. However, most TARAs are relatively informal organisations that are involved in the provision of different social and welfare activities. Nevertheless, at different times a TARA can be involved in campaigning on housing or other neighbourhood issues, sometimes in very forceful or dramatic ways. For example, I based my research in a city where there were rooftop protests by tenants opposed to the demolition of council 
p. 36. Researching Tenants and Residents Association and Local Authority Collaboration: The Value of a Grounded Theory Approach and Ethnography

houses and several coaches with tenants and residents on board (and myself on one of them) travelled to London and the Houses of Parliament to protest against the selling off of council-owned housing or its transfer to registered social landlords. ${ }^{1}$ TARA membership usually comprises all of the local authority tenants living in an area and house owners who want to be members. However, since the introduction of the Housing Act (1985) local authority tenants have had a statutory right to be consulted on housing matters that affect them or the area in which they live.

The research questions addressed in this paper concern my reasons for choosing a novel combination of a grounded theory approach and ethnography to study TARA and local authority relations and better understand how New Labour housing and tenant participation policies had impacted on TARA and local authority collaboration. The Local Government Act (1999) introduced the Best Value regime. Best Value authorities that include local authorities, national parks, and police and fire services are obliged to work with relevant stakeholders, including local taxpayers, service users, and the wider community on their plans for services and the setting of performance targets. Meanwhile, the National Framework for Tenant Participation Compacts (DETR, 1999) contains six core standards. The standards describe how compact discussions involving the local authority and TARAs should include discussions on housing services, information, tenant participation and housing management, monitoring and measuring performance in delivering housing services, tenants' groups and their needs, support for tenant participation, and local authority and tenants meetings.

The next section elaborates on the process of adapting the grounded theory method to produce a grounded theory approach used to study TARA and local authority collaboration. At the same time, there is an evaluation of the usefulness of the grounded theory method in qualitative research. Then details are provided of the use of ethnography and a grounded theory approach to systematically collect and analyse research data. This leads on to a discussion of the use of ethnography and a grounded theory approach to understand activities that occur in real life situations. Finally, some conclusions are set out including reflections on the value of a grounded theory approach and ethnography in qualitative research.

\section{Developing a Grounded Theory Approach}

It was concerns that Barney Glaser and Anselm Strauss had about an emphasis on the testing of theory at the expense of efforts to discover theory using systematically obtained and analysed data that led them to develop the grounded theory method (see Glaser and Strauss, 1967). The grounded theory method is an empirical approach to the study of social life (Clarke, 2003) where meaning is negotiated and understood through interactions with others in social processes (Starks and Trinidad, 2007). In its original form the grounded theory method embraced the idea that it was desirable to meet established standards for doing 'good science' including consistency, reproducibility, and generalisability (see Haig, 1995). But the grounded theory method is different to deductive approaches to research where the researcher starts with a theory and then collects data to determine its credibility. Instead, the researcher starts with particular experiences and identifies patterns in research data that contribute to the inductive discovery of grounded theory that emerges from the research data. As Mjoset (2005) points out too much a priori theoretical influence on researcher views can mean that the researcher is not able to distinguish easily between what are or are not significant themes or concepts in the data that they collect.

Data analysis starts with 'open' coding or the identification of items of interest and the determination of data categories. The process of analysis continues with 'axial' 
p. 37. Researching Tenants and Residents Association and Local Authority Collaboration: The Value of a Grounded Theory Approach and Ethnography

coding or constant comparison of emerging concepts to begin to reveal a set of relationships or a narrative. The process of constant comparison or relating items of data and categories to each other facilitates the identification of themes and concepts and the generation of theory (Starks and Trinidad, 2007; Urquhart, 2001) as well as insights on how understanding the whole situation influences understanding of a part of it and understanding each part in turn influences understanding of the whole (Rennie, 2000). Nevertheless, Glaser became increasingly critical of what he perceived to be too much adherence to established standards for doing 'good science' used to assess quantitative research being applied to grounded theory method research and findings (see Glaser, 1992). Meanwhile, developments in postmodernist and constructivist thinking have contributed to the formulation of different versions of the grounded theory method. For example, there are some versions of the grounded theory method that are used to show how reality is comprised of different mental constructions meaning there is no true state of affairs to be explored and explained and other versions that help to provide specific insights on class, gender, race and power issues (Annells, 1996).

It was knowledge of these different versions of the grounded theory method that caused me to adapt aspects of it to explain and better understand TARA and local authority collaboration.

\section{What's Wrong with Grounded Theory?}

Commentators, such as Goldthorpe (2000), suggest the grounded theory method is too concerned with the idea of inductivism and used by researchers who are fascinated by context at the expense of thinking about the value of decontextualising data and separating out theory from context. At the same time, some grounded theorists are too concerned about the prospect of theoretical analysis distracting the researcher and separating them from their real world studies (Layder, 1982). Consequently there is an absence of any substantial recognition of the possible value of a priori or hypotheticodeductive thinking and a misconceived emphasis on the researcher not being influenced by preconceived theoretical ideas or views when collecting and analysing data (Allan, 2003). Meanwhile, Burawoy (1991) contends that the grounded theory method is too positivist in orientation and not reflexive enough with its focus on trying to explain ever more phenomena using particular core categories or explanatory concepts. The upshot is social structures and their impact on the actions of individuals are underplayed (Layder, 1982). More attention needs to be given to history and the role of institutions in shaping the behaviour of organisations and individuals (Miller and Fredericks, 1999) as well as matters like the significance (or not) of class struggle (Annells, 1996).

Information on TARA and local authority relations and collaboration was obtained through the use of an ethnographic data collection process. The aim was to improve understanding of the role of central government institutions and how relations of power between central government, local government, and TARAs help to influence or determine how collaboration works (or not) at the local level.

\section{The Value of Ethnography}

Eisenhardt (1989) remarks that choosing somewhere where there are likely to be many surprising as well as ordinary examples of phenomena can be very edifying. I examined TARA and local authority collaboration in a large industrial city in the north of England. In this location collaboration was 'messy' because it comprised relations between organisations with very different cultures, values, and ways of working. There was also 
p. 38. Researching Tenants and Residents Association and Local Authority Collaboration: The Value of a Grounded Theory Approach and Ethnography

a history of often difficult tenant and landlord relations and conflict over the future of local authority owned housing. I was not interested in trying to discover statistically reliable relationships between different items of data or generalisable laws that would predict precisely the behaviour of organisations and individuals in a given collaborative context.

Researchers often devote much time to research that seeks to discover universal explanations for phenomena in social settings (Gephart, 2004) rather than uncovering different people's perspectives on reality (Lincoln and Guba, 1985). My intention was to obtain insights on complex and 'messy' phenomena through a focus on individuals to find out more about how they interpret their surroundings (Suddaby, 2006) and understand the environment within which they are located and create their own realities (Morgan and Smircich, 1980). I was an ethnographer who enjoyed meeting TARA activists and local authority representatives to talk with them about their experiences of 'messy' collaboration and observe their involvement in collaboration in a real life situation. Data can reflect the configuration and temporal arrangement of elements in a context (Campbell, 1986) and enable a high level of access to knowledge about phenomena that people involved in particular activities possess (Hussey and Hussey, 1997). In turn, getting to know people and experiencing events helped to improve the ecological validity or authenticity of the data collected.

Fontana and Frey (1994, p. 361) say, "Interviewing is one of the most common and most powerful ways we use to understand our fellow human beings." Ethnographic interviewing and conversations with TARA activists, councillors, and local authority employees focusing on their experiences of collaboration was an important component of the research.

\section{Interviews and Observation}

The activists interviewed were mainly past or present board members of an umbrella organisation representing the views of TARAs at a city-wide level in discussions with the local authority. Meanwhile, the councillors interviewed were mainly part of the controlling Labour group on the local authority and the local authority employees interviewed included the executive director of neighbourhoods, the head of housing (operations) and the tenant participation manager. Following pilot work with a small number of stakeholders with an interest in housing and tenant participation matters (including TARA activists and local authority representatives) a semi-structured interview schedule was developed. The schedule included questions on local political structures, strategies for influence and action, relations between organisations and individuals, governance, power, authority, resources, control and types of collaboration. I failed to switch on the recording machine on two occasions and had to telephone the interviewees concerned to arrange new interview sessions. Sometimes an interviewee did not turn up to an arranged interview session or at short notice it had to be changed or postponed.

I was also able to attend various TARA and local authority meetings and events where there were discussions about housing and neighbourhood matters. I went to board meetings of the umbrella organisation representing individual TARAs at a citywide level - including an Annual General Meeting (AGM) and an Extraordinary General Meeting (EGM) convened to decide the organisation's future - local authority cabinet and scrutiny committee meetings, and local authority convened citywide forum meetings (where TARA activists and local authority representatives gathered to discuss housing and neighbourhood matters). Observation was not always straightforward and especially early on in the research some people were suspicious of me and my motives. I was not able to attend some relevant TARA and local authority meetings that were not 
p. 39. Researching Tenants and Residents Association and Local Authority Collaboration: The Value of a Grounded Theory Approach and Ethnography

open to the public and had to decide what other meetings to attend because of demands on my time. Nevertheless, the processes of interviewing and observation were very worthwhile and provided much rich information on TARA and local authority relations and collaboration.

In addition, I kept a detailed research journal (approximately four hundred pages in total) updated on a daily basis. I strived to develop a reflexive approach that entailed thinking about my role as a researcher, relations with the researched, and impact on the research situation. I say early on that: "I do not want to simply carry out an anthropological study of neighbourhood associations ... [I feel that the research] needs to be related to a bigger theory (for example around the interface between tenant groups, the local authority, and the institutional world)" (26 February 2002). Reflecting on the progress of the research also led to some changes in the way that it was undertaken. For example, it was noted after the review of some completed interviews that: "I may be intervening too often and making interventions that are too long (also perhaps overly leading). I ... tried to modify my style in subsequent interviews" (17 January, 2003). I also made notes on my own views and experiences of the research process and tried to be honest about how my values and beliefs influenced my opinions on TARA and local authority relations and collaboration. For example, I had some sympathy for TARA actions to protect tenants' rights and ensure there was a future for council-owned housing.

I wanted to analyse the data collected and make some of the complex detail concerning the process of collaboration more explicit. At the same time, it is possible to produce, 'a theoretical account that facilitates a discussion of the general features of the topic under study and is firmly based or grounded in the data collected' (Martin and Turner, 1986, p. 142). However, I needed to find a way to make sense of the rich data on collaboration collected.

\section{Data Coding and Categorization}

I did not adopt the grounded theory method wholesale in my research of TARA and local authority collaboration. Instead, I used key aspects of the grounded theory method to develop a grounded theory approach that enabled me to analyse systematically rich data on TARA activist, councillor, and council employee experiences of collaboration and develop my own ideas concerning its meaning. My use of institutional theory (DiMaggio and Powell, 1983) and theory on power (Lukes, 1974) in the development of research questions to some extent went against the grounded theory method principle of entering the field without a strong adherence to any specific theories or ideas. I felt that central government partnership and participation policies and relations of power between collaborating organisations and individuals would impact significantly on collaborative outputs and outcomes.

The data analysis process began with the transcription of taped interview sessions saved as word files on my desktop computer. In total forty-two interviews were completed with forty-seven interviewees. The job of transcribing was arduous (approximately three hundred hours of work) and often frustrating. On a number of occasions it was difficult to understand what people were saying and sections of tape had to be rewound and replayed, sometimes many times over, and not always with a successful outcome. Sometimes there were problems with noise in the background such as the pneumatic drill used in the street adjacent to the café where an interview with one TARA activist took place. The next part of the data analysis involved coding sections of text which was the start of an iterative and mainly inductive process of data sorting (since it was influenced by my interest in the role of institutions and power in 
p. 40. Researching Tenants and Residents Association and Local Authority Collaboration: The Value of a Grounded Theory Approach and Ethnography

shaping inter-organisational relations) to start to reveal patterns and concepts in the data.

I did not use all of the different coding processes outlined in the original grounded theory method texts. Instead, I simplified the labelling and coding process and used different coloured highlighter pens and comments in the margins of transcribed interview texts to differentiate between different types of views or ideas relating to the way that collaboration worked (or not). Then different sections of text, cut into pieces with a pair of scissors and sorted into piles that corresponded to emerging categories or themes, helped to reveal relationships between phenomena or concepts such as power and control, negotiation strategies, culture and values, and types of collaboration. Next, I went through the different piles of data and compared items within and between piles then exchanged and added or subtracted items to facilitate the development of more coherent data categories and data families where categories were related to each other in some way. The coding and categorisation of data was a time-consuming and difficult process. I often went back to the data to compare items with each other to avoid as far as possible overlooking relationships. Figure 1 provides an outline of the nine data families identified.

\section{Figure 1: Data Families and the Focus of the Themes they cover}

\section{Data Families and Themes}

- resources (who has control over important funds, information, and expertise)

- the Tenant Participation Compact (its purpose and implementation)

- structure and process (collaborative arrangements and how collaboration is managed)

- power and negotiations (who has power and how it impacts on deliberations in collaboration)

- TARA activists and leadership (the role of the activist in representing tenants)

- conformity and conflict (the pressure to conform and dealing with conflict)

- institutions and organisations (the role of institutions and TARA autonomy or incorporation)

- contracts and measurement (rules and regulations and the monitoring and evaluation of performance)

- culture and values (different institutional and organisational cultures and values and on collaboration at the local level).

In the study location the local authority abandoned the traditional committee system and replaced it with an elected council leader and cabinet after the introduction of the Local Government Act (1999). Ten executive councillors each have charge of a different cross-cutting thematic portfolio of functions and services. The councillor who was the Liberal Democrat leader of the opposition and shadow spokesperson for housing suggested that, "Under the cabinet structure it is much harder for them [activists] to engage ... in the cabinet process ... [and] strategic decisions ... There is a scrutiny committee that deals with housing but it is not just housing [it is] ... development, environment, leisure services as well'. This is an example of a statement linked to the theme that emerged on structure and process and indicates the tensions between the new cabinet way of working and opportunities for activists to get access to politicians and influence decision-making processes.

Meanwhile, the Labour councillor who was the local authority's cabinet member for education said, 'You are working to the agenda of a national government. I mean as a local authority ... there are limits to what you can do locally ... and that is the reality. It 
p. 41. Researching Tenants and Residents Association and Local Authority Collaboration: The Value of a Grounded Theory Approach and Ethnography

is not always possible to do what you want because we do not work in a decentralised culture we work in a centralised culture'. This sort of statement is related to the theme on institutions and organisations and the theme on culture and values. A relatively powerful central government and a dominant culture and values will influence or determine how TARAs and local authorities collaborate. However, the local authority's head of housing (operations) felt that the relationship with the tenants and residents movement was similar to 'The relationship between parents and adolescent children'. This is a remark that fits with the theme on activists and leadership because it raises issues concerning the role of the activist and the local authority's management of its relations with TARAs.

An academic, at Sheffield Hallam University, interested in local regeneration and housing issues said, 'The agenda is still heavily set and the community partners are more often than not being invited into something where key decisions have already been taken. There is a question of them being enlisted rather than engaged'. Here the focus is on the theme concerning power and negotiations and the extent to which activists are able (or not) to get their priorities onto relevant agendas for discussion and how much influence they have in deliberations. It was suggested by a community consultant, working for an organisation providing capacity building assistance to TARAs on behalf of the local authority, that it was often difficult for TARA activists to voice their real concerns and get the local authority to take them seriously. He said, 'Tenants do struggle to convince, particularly housing professionals, that they have a body of knowledge and experience that is actually worthwhile, meaningful and valuable'. Again the theme on culture and values is relevant when thinking about the relationships that exist between professionals and activists and what types of knowledge and experience or beliefs are valued (or not). In turn, the local authority's tenants' participation manager remarked that: "What tends to happen is that we try and create mirrors of ourselves ... and set up ... groups [TARAs] that tend to very much mirror how we as a council work in terms of the bureaucracy." This remark can be related to the theme on contracts and measurement and how TARAs need to fit with the local authority's ways of working and are assessed on how closely they meet its expectations regarding what a TARA should look like and be doing.

A novel combination of aspects of the grounded theory method and ethnography can be used to systematically collect and analyse a very large amount of rich information on phenomena in a real life context. The in-depth insights on events and the explanatory concepts that emerge can help to improve understanding of what is happening in a 'messy' and complex situation.

\section{Applying ‘A Priori’ Thinking to Grounded Theory}

I developed and used a novel grounded theory approach and ethnography to examine and understand TARA and local authority collaboration. It is a methodology that facilitates the well planned and systematic collection and analysis of a large amount of rich data on different sorts of relationships and activities in 'messy' real life situations. At the same time, the processes that are used to make sense of the information that is collected need to be described in detail and can be scrutinised by others interested in knowing how data categories, families and themes begin to emerge. A high degree of transparency and openness about the conduct of research and the analysis of data is also maintained by rigorous elaboration on the processes involved in the labelling and continuous comparison of different items of data to reveal patterns and concepts. Burawoy (1991) remarked that the grounded theory method might not always be sufficiently reflexive with its emphasis on trying to explain more and more phenomena using an array of categories or explanatory concepts. Keeping a detailed research 
p. 42. Researching Tenants and Residents Association and Local Authority Collaboration: The Value of a Grounded Theory Approach and Ethnography

journal that contains comments on the progress of the research, successes and failures, and the researcher's views on their role and impact on the research situation helps to provide many useful insights on the development of ideas and the trajectory of investigations.

At first the ethnographic researcher is keen to seek out opportunities to obtain the backing of key gatekeepers and build rapport that enables them to gain access to other relevant persons. Then the ethnographer can spend time getting to know people on the ground and learning about a community or neighbourhood and how history, context, structures, and relationships interconnected in obvious and subtle ways are constantly changing on a daily or moment-to-moment basis. However, it was previously noted that commentators such as Allan (2003) have suggested that there can be a problematic absence of any appropriate recognition of the value of a priori thinking in grounded theory research. My intention was to avoid being beholden to a grounded theory method in its entirety that might entail using procedures that were not relevant to the particular research being undertaken. I had developed some theoretical ideas prior to conducting my research investigating TARA and local authority collaboration and like Goldthorpe (2000) felt it was important to consider how emergent themes and concepts would be separated out from contextual considerations to develop theory. I was interested in institutions and how they could influence or determine organisational relations at the local level and in power and how it was shared or used in TARA and local authority collaboration.

The aim was to develop a grounded theory approach that provided an explicit and convenient framework for the breaking down of data, its organisation into categories and families, and reformulation as themes and concepts that helped to explain different phenomena in a complex and 'messy' situation. However, some of the data collection and analysis process was not rigidly aligned with the grounded theory method originally described by Glaser and Strauss (1967). In particular, there was extra flexibility built into the data collection and analysis process that enabled me to develop my own thinking on labelling and coding which sometimes did not correspond with the order or precise way that the grounded theory method set things out. Layder (1982) pointed out that there could be a tendency to underplay social structures and their impact on the actions of individuals in grounded theory method analyses. The development of some theoretical ideas relating to institutions and power that might help to improve understanding of collaborative phenomena before starting the research in earnest proved useful and helped to counter this criticism. A focus on institutional pressures and 'organizational isomorphism' helped to show how institutions affect organizations and individuals. It also added a much-needed perspective on the political struggles for organizational power and survival. The term 'isomorphism' describes a constraining process that forces one unit in a population to resemble other units that face the same set of environmental conditions. ${ }^{2}$ DiMaggio and Powell (1983) identified three types of institutional pressure affecting organizations that can cause 'organizational isomorphism'. First, there is the coercive pressure to act in certain ways exerted on an organization by an institution or organization on which it is dependent. Second, there is the mimetic pressure to act in certain ways exerted on an organization that causes it to imitate other organizations perceived to have been successful in obtaining the legitimacy or resources they need to function effectively. Third, there is the normative pressure to act in certain ways exerted on an organization by professionals and influential others who have an interest in its affairs.

It is also important to think about the different dimensions of power that might help to ensure issues enter or are kept off different agendas, cause or prevent conflict, and underpin decision-making or non-decision-making processes. Lukes (1974) devised a 
p. 43. Researching Tenants and Residents Association and Local Authority Collaboration: The Value of a Grounded Theory Approach and Ethnography

three-dimensional view of power. First, institutions in particular and sometimes organizations or individuals can succeed in preventing potential issues from entering into the political arena (p. 21). Second, this shaping of the political arena sometimes occurs in the absence of observable conflict. However, latent conflict can remain that comprises a contradiction between the interests of those exercising power and the real interests of those they exclude (p. 22). Third, an assumption exists that suggests that if people have no grievances then they have no interests that the use of power can harm. Nevertheless, a process of non decision-making may occur in situations where people do not have grievances because their views and preferences conform to established practice and they cannot imagine any alternative to the situation they are in (p. 24).

Theory on institutions and power provided the ideas and concepts used to understand TARA and local authority relations. I did what Miller and Fredericks (1999) have suggested and considered how history, institutions and structures at the macrolevel impacted on organisations and also reflected on matters at the level of the individual. In the 'messy' real life situation there is a complex interplay between dominant institutionalized languages, values, and beliefs, the power and control that different groups have over important resources and agendas, and the shape of interorganisational relations and collaboration.

\section{Conclusions}

The unusual but potentially powerful combination of a grounded theory approach and ethnography can be used to undertake a robust and in-depth examination of community and neighbourhood activities and people's views on different matters. It is a methodology that includes interviews and observation and a focus on making explicit the process of grouping (or not) ideas and opinions and the way various interconnections between them are established. Much researcher time is spent developing empathy and building rapport with individuals, getting to know the history of a place, and discovering facts and stories. Then there is the more structured and intellectual processes associated with the scrutiny of information, its segregation and categorisation, and interpretation. These processes do not deny the value of having theoretical views from the outset that can be used to help establish a framework for understanding phenomena. Eventually, some assertions might be made about the transferability of findings based on the way that the themes and concepts that emerge relate to each other and help to explain events that will occur at different times in other similar circumstances. In addition, research findings can contribute to the enhancement of existing theory or the generation of new theory.

The key point to remember is that it is feasible to adopt or jettison different aspects of the grounded theory method in order to construct a grounded theory approach that is better suited to your own research style and the particular research questions that you want to address. Moreover, some of the criticisms of the grounded theory method can be addressed including a possible lack of emphasis on the role of institutions, researcher impact on the research situation and reflexivity, and a failure to appreciate the potential value of a priori theoretical insights that might help to explain research findings. It is possible to use a grounded theory approach and ethnography to embrace relevant aspects of deductive and inductive analytical processes to produce grounded findings that are explained using appropriate theoretical ideas or concepts. However, tensions can develop concerning the use of theory to develop a priori ideas about the different factors that might influence or determine how organisations and individuals act and work together (or not) and the interpretation of data obtained in a real life situation. 
p. 44. Researching Tenants and Residents Association and Local Authority Collaboration: The Value of a Grounded Theory Approach and Ethnography

But it is feasible for researchers to use different theories to improve understanding of a situation and carefully collect and categorise data to tease out similarities and differences and allow themes and concepts to emerge. In particular, the reflexive researcher can keep a research journal and attempt to understand how different understandings of the researcher, the research, and the researched emerge as the research progresses (Riley et al., 2003). They must set out their interests and motives for wanting to undertake a particular piece of research. The aim is to use interpretative and imaginative aspects of their research to explain phenomena and make explicit their own feelings about the research. Meanwhile, the researcher can use different theoretical and intellectual strategies to challenge their own assumptions concerning research methodology and methods (Marcus, 1994). In particular, the quality of qualitative research improves when the researcher thinks about their role, values, beliefs and biases, and how they impact on data collection and analysis (Guba and Lincoln, 1994).

\section{Notes}

1 Registered Social Landlord is a term introduced in the Housing Act (1996) to describe an independent, not-for-profit, local housing company, trust, cooperative, or association that is registered with the Tenant Services Authority (a central government backed regulatory agency).

2 The term 'isomorphism' was first used in chemistry to describe the formation of identical crystalline structures.

* Correspondence Address: Rob Dalziel, Research Fellow, Institute of Local Government Studies, School of Government and Society, 9th Floor, Muirhead Tower, University of Birmingham, Edgbaston, Birmingham, B15 2TT. Email: r.dalziel@bham.ac.uk.

\section{References}

Allan, G. (2003) A critique of using grounded theory as a research method. Electronic Journal of Business Research Methods, 2, 1, 1-10.

Annells, M. (1996) Grounded Theory Method: Philosophical Perspectives, Paradigm of Inquiry, and Postmodernism. Qualitative Health Research, 6, 3, 379-393.

Burawoy, M. (1991) Ethnography Unbound. Berkeley: University of California Press.

Campbell, D.T. (1986) Relabeling Internal and External Validity for Applied Social Scientists. New Directions for Program Evaluation, Fall 1986, 31, 67-77.

Clarke, A.E. (2003) Situational Analyses: Grounded Theory Mapping After the Postmodern Turn. Symbolic Interaction, 26, 4, 553-576.

DETR (1999) National Framework for Tenant Participation Compacts. Department of the Environment, Transport and the Regions.

DiMaggio, P.J. and Powell, W.W. (1983) The Iron Cage Revisited: Institutional Isomorphism and Collective Rationality in Organizational Fields. American Sociological Review, 48, 2, 147-160.

Eisenhardt, K.M. (1989) Building Theories from Case Study Research. Academy of Management Review, 14, 4, 532-550.

Fontana, A. and Frey, J.H. (1994) Interviewing: The Art of Science, in: N.K. Denzin and Y.S. Lincoln (eds) Handbook of Qualitative Research. London: Sage Publications Ltd. 
p. 45. Researching Tenants and Residents Association and Local Authority Collaboration: The Value of a Grounded Theory Approach and Ethnography

Gephart, R. (2004) Editorial: Qualitative Research and the Academy of Management Journal. Academy of Management Journal, 47, 3, 237-238.

Glaser, B.G. (1992) Basics of Grounded Theory Analysis: Emergence vs. Forcing. Mill Valley, CA: Sociology Press

Glaser, B.G. and Strauss, A.L. (1967) The Discovery of Grounded Theory: Strategies for Qualitative Research. Wiedenfeld and Nicolson.

Goldthorpe, J.H. (2000) On Sociology. Oxford: Oxford University Press.

Guba, E.G. and Lincoln, Y.S. (1994) Competing Paradigms in Qualitative Research, in: N.K. Denzin and Y.S. Lincoln (eds) Handbook of Qualitative Research. London: Sage Publications Ltd.

Haig, B.D. (1995) Grounded Theory as Scientific Method. Philosophy of Education Yearbook, 1995.

Housing Act (1985) An Act to consolidate the Housing Acts (except those provisions consolidated in the Housing Associations Act 1985 and the Landlord and Tenant Act 1985), and certain related provisions, with amendments to give effect to recommendations of the Law Commission.

Hussey, J. and Hussey, R. (1997) Business Research: A practical guide for undergraduate and postgraduate students. Basingstoke: Palgrave.

Layder, D. (1982) Grounded Theory: A Constructive Critique. Journal for the Theory of Social Behaviour, 12, 1, 103-123.

Lincoln, Y.S. and Guba, E.G. (1985) The Only Generalization is: There is no Generalization, in: R. Gomm, M. Hammersley and P. Foster (eds) (2000) Case Study Method. London: Sage Publications Ltd.

Local Government Act (1999) An Act to make provision imposing on local and certain other authorities requirements relating to economy, efficiency and effectiveness; and to make provision for the regulation of council tax and precepts, 27 July 1999, http://www.opsi.gov.uk/ACTS/acts1999/ukpga_19990027_en_1 (accessed 18 March 2002).

Lukes, S. (1974) Power: A Radical View. Basingstoke: The Macmillan Press Ltd.

Marcus, G.E. (1994) What Comes (Just) After 'Post'?: The Case of Ethnography, in: N.K. Denzin and Y.S. Lincoln (eds) (1994) Handbook of Qualitative Research. London: Sage Publications Ltd.

Martin, P.Y. and Turner, B.A. (1986) Grounded Theory and Organizational Research. The Journal of Applied Behavioral Science, 22, 2, 141-157.

Miller, S.I. and Fredericks, M. (1999) How Does Grounded Theory Explain? Qualitative Health Research, 9, 4, 538-551.

Mjoset, L. (2005) Can Grounded Theory Solve the Problems of its Critics? Sosiologisk tidsskrift, 13, 379-408.

Morgan, G. and Smircich, L. (1980) The Case for Qualitative Research. Academy of Management Review, 5, 491-500.

Rennie, D.L. (2000) Grounded Theory Methodology as Methodological Hermeneutics: Reconciling Realism and Relativism. Theory and Psychology, 10, 4, 481-502.

Riley, S., Schouten, W. and Cahill, S. (2003) Exploring the Dynamics of Subjectivity and Power Between Researcher and Researched. Forum: Qualitative Social Research, 4, 2. www.qualitative-research.net/fqs/-texte/2-03/2-03rileyetal-e.htm (accessed 2 June 2004).

Starks, H. and Trinidad, S.B. (2007) Choose Your Method: A Comparison of Phenomenology, Discourse Analysis, and Grounded Theory. Qualitative Health Research, 17, 10, 1372-1380.

Suddaby, R. (2006) What grounded theory is not. Academy of Management Journal, 49, 4, 633-642.

Urquhart, C. (2001) An Encounter with Grounded Theory: Tackling the Practical and Philosophical Issues, in: C. Urquart (2001) Qualitative Research in IS: issues and trends. Hershey, PA, USA: IGI Publishing. 